\title{
Hegel e a cidadania
}

Danilo Vaz-Curado. R. M. Costa*

DOI: $10.20399 / \mathrm{P} 1982-999 X .2015 v 1 n 2 p p 112-123$

Resumo: O presente texto objetiva explicitar como o tema da cidadania se desenvolve na Filosofia do Direito de Hegel. Para a realização deste propósito se percorrerá o caminho que conduz da Família ao Estado, passando pela sociedade civil. Espera-se demonstrar como em Hegel há importantes pistas para a compreensão das dificuldades que a cidadania encontra para se efetivar em contextos reais. Palavras-Chaves: Hegel, Ação, Cidadania, Filosofia, Esferas.

Abstract: This paper aims to explain how the theme of the Citizenship develops in Hegel's Philosophy of Right . To carry out this purpose will traverse the path that leads from the family to the State, through Civil society. Expected to demonstrate as in Hegel there are important clues for understanding the difficulties that citizenship lies to be effective in real contexts.

Key-Words: Hegel, Action, Citizenship, Philosophy, Globe.

O objeto da presente reflexão possui como núcleo chave duas palavras: Hegel, conhecido filósofo alemão, e cidadania, condição de todo aquele que é cidadão, compreendido este como o membro de uma determinada coletividade política capaz de exercitar de modo direito ou indireto, direitos e deveres, sejam públicos ou privados.

O objetivo do presente trabalho é demonstrar como em Hegel desenvolve-se um conceito de cidadania ainda atual, o que de modo algum significa diretamente aplicável, para a compreensão do próprio modo no qual atualmente encontra-se a ideia de cidadania, ao mesmo tempo, que se entende que alguns ou muitos dos pressupostos assumidos por Hegel estão na base da atual compreensão de cidadania.

Por fim, espera-se contribuir para uma melhor construção do conceito de cidadania, ad intra à reflexão hegeliana, explicitando ponto tão pouco visitado na Hegel-Forschung, e ad extra, no sentido da contribuição das reflexões sobre a cidadania para além do hegelianismo, na medida em que se assume um determinado valor de universalidade na reflexão filosófica.

*Doutor em Filosofia pela UFRGS, Professor da Universidade Católica de Pernambuco/Brasil, email de contato: danilo@unicap.br. A presente pesquisa contou com o suporte financeiro da Fundação de Amparo à Ciência e Tecnologia do Estado de Pernambuco/FACEPE, através do processo APQ-0132-7.01/14. 
Para a consecução do objetivo traçado é mister a compreensão do locus - o Espírito Objetivo - no qual se desenvolve a reflexão hegeliana referente à cidadania. Pediremos a vênia ao leitor para o corte metodológico que faremos, pois, renunciaremos de partida a elaborar nossa reflexão sobre a Enciclopédia das Ciências Filosóficas, tomo III sobre o Espírito, e as Vorlesungen über Geschichte [Lições sobre a Filosofia da História], locais, aparentemente mais apropriados para a reflexão acerca do tema cidadania, e nos limitaremos à Filosofia do Direito de 1821.

Deste modo, o presente trabalho dividir-se-à em dois momentos: (i) determinação do objeto e objetivo da Filosofia do Direito, com vistas à posterior compreensão da (ii) cidadania, tal como desenvolvida por Hegel.

\section{A Filosofia do Direito de Hegel}

Hegel afirma que a tarefa da Filosofia é traduzir o tempo em conceitos. Dentro da estruturação do sistema hegeliano exposto na Enciclopédia, este divide-se de modo sistemático em três grandes grupos expressivos: a Lógica, a Natureza e o Espírito. A proposta hegeliana de tradução de seu tempo em conceitos atinge o cume de sua reflexão na tematização acerca do conceito de Espírito, mais precisamente no Espírito Absoluto.

Pode-se afirmar que, o Absoluto enquanto Espírito possui três modos de existência e três modos de conhecimento. Enquanto Espírito, o absoluto, existe como subjetividade na seção Espírito subjetivo; como subjetividade em mediação com as instituições enquanto objetivações de sua vontade livre no Espírito Objetivo, e enquanto auto-exposição filosófica do pensamento que se pensa no Espírito Absoluto.

Todavia, se a economia do sistema possui três grandes formas da existência se fazer efetiva, ao mesmo tempo possui reciprocamente três modos desta mesma efetividade se dar a conhecer ${ }^{1}$, de modo que; enquanto Espírito, o Absoluto se apreende pela intuição na arte, se expressa na representação pela Religião e se conhece pela ciência na Filosofia.

Assim, a Filosofia do Direito de Hegel ocupa, na Enciclopédia, o lugar equivalente ao Espírito Objetivo, ou seja, o momento de mediação entre a subjetividade compreendida em si mesma [Espírito subjetivo], e o Espírito Absoluto. Nesta

\footnotetext{
${ }^{1}$ Aqui o leitor deve ter bastante atenção aqui no constante jogo de elevações e suprassunções.
} 
perspectiva, a Filosofia do Direito tem, por assim dizer, a função de desenvolver o pensamento ético, social e político, ou seja, os modos de mediação das vontades livres dentro das instituições. Tal lugar central da Filosofia do Direito conduziu Hegel a tematiza-la de forma única no conjunto de sua obra publicada em vida.

Tal caráter inédito da Filosofia do Direito na exegese hegeliana não se deve apenas pela amplitude dos temas que ela se propõe a tratar, como: o direito abstrato, a moralidade, a eticidade, a vontade livre, o Estado etc., mas ante ao fato de que é apenas a Filosofia do Direito, enquanto exposição do Espírito Objetivo, que foi desenvolvida em sua inteireza de modo mais exaustivo fora e independente da Enciclopédia das Ciências Filosóficas.

Hegel na própria Enciclopédia adverte que não se estenderá muito no tratamento destes temas atinentes ao Espírito Objetivo, pois já os houvera feito de modo satisfatório em sua Filosofia do Direito $^{2}$, pensa-se, portanto, plenamente justificável a escolha da Filosofia do Direito de 1821 para a tematização da cidadania a partir do referencial hegeliano; primeiro por ser no Espírito Objetivo onde a cidadania se faz explicitar de modo mais pungente e, segundo, porque mesmo havendo outros 'locais' para esta clarificação conceitual, Hegel não os considerou suficientemente desenvolvidos.

Dentro desta especificação espacial e temática da Filosofia do Direito dentro do contexto geral do sistema hegeliano, e ainda exterior à reflexão, passa-se, então, ao objeto e o objetivo da Filosofia do Direito de Hegel em 1821, dentro da qual se desenvolve a cidadania na compreensão hegeliana.

Hegel nos diz que "A ciência filosófica do direito tem por objeto a ideia do direito, o conceito do direito e sua efetivação"”. Logo, se depreende que o tema de análise e desvelamento filosófico da obra é o Direito, compreendido este não como um mero dever-ser e, ou conjunto positivo de leis que se aplicam num dado tempo e espaço, mas, desde uma perspectiva filosófica, como Ideia que se desenvolve e exterioriza-se no processo mesmo de sua efetivação.

O uso dos termos nesta passagem citada de Hegel não deixa margens de dúvidas de que o objeto da obra é o direito enquanto reino de efetivação da vontade livre, pois fala-se do conceito de direito e sua efetivação desde uma apreensão filosófica do direito.

${ }^{2}$ Cf., Hegel, Enciclopédia das Ciências Filosóficas, § 487.

${ }^{3}$ Hegel, Filosofia do Direito, $§ 1$. 
Para fins de compreensão do sentido do que está em jogo, vontade livre é aquela que tem apenas a si própria (a vontade, não esta ou aquela vontade) como pressuposto. Hegel textualmente aduz que

O terreno do direito é, em geral, o espiritual, e seu lugar e seu ponto de partida mais precisos são a vontade, que é livre, de modo que a liberdade constitui sua substância e sua determinação e que o sistema do direito é o reino da liberdade efetivada, o mundo do espírito produzido a partir dele mesmo, enquanto uma segunda natureza. ${ }^{4}$

Hegel não se preocupa com um específico ou empírico sistema de direitos em particular, mas com a ideia de direito, ou seja, o reino da liberdade realizada, a vontade que se exterioriza e constitui o solo próprio da humanidade como um espaço de razões enquanto mundo determinado pela vontade livre.

Esta conexão entre direito e vontade é explicitada por Hegel no $§ 29$ da $F D$ ao afirmar que "De modo geral, que um ser-aí seja o ser-aí da vontade livre, isso é o direito. - Ele é, por isso, de modo geral, a liberdade enquanto ideia." ${ }^{5}$ Para Hegel o direito é o Dasein - o ser-aí - da vontade livre, sua forma objetiva/subjetiva e subjetiva/objetiva.

Enquanto estruturada num espaço de determinações mediatizadas da vontade, o mundo do direito apreende a vontade não pela mera causalidade, própria às ciências naturais, mas pela causalidade das conexões lógico-volitivas da vontade que se exterioriza, ou seja, por razões, numa espécie de causalidade da liberdade, se Hegel fosse lido em chave kantiana.

Neste ponto, demarca-se uma clara ruptura de Hegel com pensadores que ora naturalizam o fenômeno jurídico como sendo algo meramente natural, ou, ora o compreendem de forma hipotética, como um mero postulado da razão. Em Hegel, o Direito e a sua efetivação têm a pretensão de estabelecer um marco de compreensão do fenômeno jurídico não redutível à lei, nem meramente disperso na contingência histórica.

O direito pretende ser compreendido numa perspectiva especulativa, que nem se reduz a um normativismo, a um decisionismo, ou a um descritivismo hipotético; daí que a finalidade da Filosofia do Direito é ao mesmo tempo explicitar o ser-aí da vontade

\footnotetext{
${ }^{4}$ Hegel, Filosofia do Direito, $\S 4$.

${ }^{5}$ Hegel, Filosofia do Direito, § 29.
} 
livre, suas instituições e o modo como a objetividade das instituições se efetivam na história através da vontade livre, ou seja, o Direito.

Neste sentido, pode-se seguramente afirmar que a Filosofia do Direito de Hegel contém ao mesmo tempo: um manual de direito natural, um tratado de ciência política, uma ética e uma teoria da vontade, sem reduzir-se a nenhuma destas apreensões do seraí da vontade livre.

Estabelecidos, nos seus traços gerais, os sentidos de objeto e objetivo da Filosofia do Direito, passaremos a estruturação e ao potencial de diagnose do conceito Cidadania no contexto da Filosofia do Direito.

\section{Estruturação e atualidade do conceito de Cidadania nos Grundlinien de Hegel}

A Filosofia do Direito de Hegel desenvolve a dinâmica da subjetividade em mediação com as instituições por um intenso processo de autodiferenciação dos diversos níveis do ser-aí da liberdade. Ludwig Siep aduz sobre a FD que

A autodiferenciação, a diferenciação interna num sistema autônomo que possui uma lógica própria, isto é, a objetivação normativa interna, é para a filosofia hegeliana o princípio da efetividade e princípio de sua conceitualização científica. Entretanto, são diferentes o modo de diferenciação e a objetivação lógica a depender se nós estamos [no sistema hegeliano] na natureza, no mundo social, na cultura ou no pensamento puro. ${ }^{6}$

É sabido que a Filosofia do Direito se compõe dos seguintes momentos: (i) Direito abstrato, (ii) Moralidade e (iii) Eticidade, e que dentro deste terceiro há uma importante subdivisão interna na qual coloca-se a Família, a Sociedade civil e o Estado.

Para a compreensão da Cidadania no projeto da Filosofia do Direito hegelina é preciso o entendimento, mesmo que a traços largos, do processo de autodiferenciação interna a que o Espírito se submete no curso de seu percurso de desenvolvimento, pois a própria noção de cidadania se gesta neste processo interno de autodiferenciação.

\footnotetext{
${ }^{6}$ Ludwig Siep, Die Aktualität der praktischen Philosophie Hegels, p. 191, no original „Selbstunterscheidung, interne Differenzierung in selbständige Systeme, die einer eigenen „Logik” bzw. inneren sachgesetzlichkeit gehorchen, ist für die Hegelsche Philosophie das Prinzip der Wirklichkeit und ihres wissenschaftlichen Begreifens. Allerdings ist die Art der Differenzierung und die Sachlogik verschieden, je nachdem ob wir uns im Bereich der Natur, der sozialen Welt, der Kultur oder des reinen Gedankens befinden."
} 
Para tanto, apresentaremos os traços gerais da configuração da vontade livre no Direito abstrato e na moralidade, para nos concentrarmos com maior vigor no desenvolvimento da ideia de Cidadania, ao nível da Eticidade.

O Direito abstrato se constitui como uma grande expressão conceitual da vontade mediante a propriedade e o contrato enquanto meios de aquisição e alienação de bens desde um princípio hipotético, no qual a vontade livre se relaciona e se faz efetiva através das coisas, daí seu caráter abstrato. A vontade se relaciona com as coisas exteriores em relações de exterioridade. No direito abstrato o processo de autodiferenciação normativa da vontade vai da interioridade da pessoa de direito à exterioridade das coisas do mundo.

A moralidade tem por objeto a estruturação interna da ação e suas formas de efetivação desde a perspectiva do tornar efetiva a ideia do bom e do justo na perspectiva individual da consciência moral. Assumido este pressuposto, a vontade livre relacionase de modo interno com as situações e fatos exteriores, avaliando-os desde um ponto de vista moral, logo, interno ao sujeito. No processo de autodiferenciação próprio do agente moral as determinações veem da exterioridade do mundo e são avaliadas desde a perspectiva interna dos condicionantes morais.

É um lugar, já pacífico, na Hegel-Forschung após os estudos de Karl-Heinz Ilting ${ }^{7}$ que o direito abstrato e a moralidade desenvolvem e incorporam a perspectiva da direito natural ou racional da modernidade na obra hegeliana. Tal perspectiva assume o postulado hobbesiano e kantiano do homem como titular de direitos e o reconhecimento de normas morais como condição fundamental para a estruturação da sociabilidade moderna.

Para Hegel as duas primeiras partes da Filosofia do Direito - Direito abstrato e moralidade - têm por finalidade expor como a modernidade supera no plano macroorganizacional o modelo de um consenso tradicional por um consenso racional, e como as relações de autoridade baseadas na tradição são substituídas por normas racionais universalistas.

Deste modo, Hegel busca expor como os modernos, em princípio livres, e iguais, estabelecem sua autogestão de modo racional por meio de leis, objetivamente determinadas, segundo o tribunal universalista da razão.

\footnotetext{
${ }^{7}$ Karl-Heinz Ilting, The structure of Hegel's Philosophy of Right, in Hegel's Political Philosophy. Problems and Perspectives, London: 1971, p. 91 e segs.
} 
Hegel reconhece o grande ganho dos novos Tempos, a submissão e a avaliação de todas as instituições ante o princípio da subjetividade e seu primado secularista, esclarecido, individualista e racionalmente objetivo, cuja maior expressão é a ficção de um estado pautado em sua fundação por um consenso racional, o Contrato social.

Dentro deste quadro de apreciação moderna dos grandes temas da tradição do Direito Natural nos grandes temas da Filosofia do Direito, Hegel mediante a eticidade recuperará temas aristotélicos. Ou seja, é apenas ao nível da Sittlichkeit que Hegel retomará os caros temas da tradição da filosofia política da antiguidade.

Ocorre, de fato, uma intensa mudança de perspectiva na Filosofia do Direito hegeliana das seções Direito abstrato e moralidade para a seção Eticidade. Hegel promove nos dois primeiros momentos uma espécie de acerto de contas com a modernidade, para com a seção Eticidade, promover um verdadeiro züruck zu Aristóteles, retomando à antiga divisão do Estagirita de: família [Oikos], sociedade civil [koinonia politikê ou societas civilis] e Estado [Polis ou civitas].

Denis Rosenfield na apresentação à edição brasileira da Filosofia do Direito de Hegel afirma que

Devemos estar atentos para o fato da Eticidade ser, para Hegel, o conjunto das relações familiares, sociais, civis, jurídicas, políticas, religiosas e estatais. Seu conceito é tão abrangente, que inclui desde relações institucionais até as crenças realizadas na objetividade do mundo. Ou seja, a Eticidade corresponde à liberdade realizada nas crenças e instituições, abarcando, objetivamente, essas diferentes esferas da atividade humana.

E é nesta mudança de perspectiva que se centraliza o potencial de diagnose da reflexão hegeliana acerca da Cidadania, pois, para Hegel o diagnóstico moderno de uma sociedade centralizada num ideal meramente subjetivo, racional abstrato não se faz suficiente para a compreensão de uma sociedade já a sua época complexa e plural.

Dentro deste quadro, Hegel compreende como falsa uma mera contraposição entre antigos e modernos. Os novos tempos são, em sua compreensão, muito mais complexos que os dualismos ou as alternativas pautadas numa estrita crença em torno do papel do indivíduo ou do mercado, do Estado ou da sociedade.

Passemos agora à como Hegel na Filosofia do Direito estrutura as condições de realização da cidadania, e para tanto no serviremos da anotação ao $§ 190$, onde se define o processo de diferenciação interna, ou autodiferenciação normativa do social, segundo papéis e níveis de realização valorativa, nos seguintes termos: 
[...] No direito, o objeto é a pessoa, no ponto de vista moral é o sujeito, na família é o membro da família, na sociedade civil-burguesa em geral é o Bürger (enquanto bourgeois) - aqui, no ponto de vista dos carecimentos (cf. § 123 anotação), é o concreto da representação, que se chama homem; portanto é aqui a primeira vez e também propriamente apenas aqui que se fala do homem nesse sentido.

Deste ponto de vista e assumindo uma definição quase minimalista de Cidadania como o estatuto do indivíduo que possui o direito [não redutível aqui a expressão Direito em sua compreensão à Lei] a ter direitos civis e políticos e que têm como contrapartida o dever de exercê-los nos espaços familiares, econômico e político, a perspectiva posta por Hegel já se coloca no cerne do problema contemporâneo, ou seja, há diversos estatutos ou níveis de efetivação da cidadania!

Tal caráter múltiplo do exercício da cidadania resulta do próprio processo de autodiferenciação do social em diversas esferas dotadas de determinações próprias, com papéis, expectativas normativas e pretensões morais diversas. Deste modo, antevê-se que a compreensão da Cidadania em Hegel é perpassada por diversas esferas internas de realização e efetivação da noção, a qual traduz-se na família por laços de sociabilidade como membro [Glied]; na sociedade civil como o indivíduo econômicopossessivo - fim em si mesmo - o Bürger, e , ao nível do Estado, como o cidadão [Citoyen].

Deste modo, Hegel compreende que o processo de autorrealização da vontade livre implica o processo de autodiferenciação interna das pautas morais e dos níveis da sociabilidade segundo diferentes compromissos, pautas, expectativas e pretensões normativas, de modo que, ao adentrar na seção Eticidade, a cidadania na Filosofia do Direito oscila entre o altruísmo particularista ${ }^{8}$ [das relações não patrimoniais próprias à família], ao egoísmo generalizado, próprio da sociedade civil, enquanto mundo do trabalho e do mercado, tudo em mediação com o universalismo mediatizado do sujeito que se sabe livre porque se reconhece nas instituições objetivas como efetivações de sua vontade em mediação com as demais vontades, o cidadão.

A cidadania desempenha assim, em Hegel, a função de desenvolver o princípio da subjetividade, na sua Filosofia do Direito designado como o ser-aí da vontade livre entre três grandes paradigmáticas configurações da vontade livre, $(i)$ a universalidade imediata da família, primeira raiz ética da eticidade, (ii) a universalidade perdida em seus extremos, enquanto movimento do exercício do cidadão [Bürger] no mundo do

\footnotetext{
8 Sigo aqui, em geral, a tese de Vittorio Hösle exposta em in., Anspurch und Leistung von Rechtsphilosophie, p. 183.
} 
trabalho e das relações econômicas, e a (iii) universalidade efetiva do cidadão, partícipe do Estado, momento no qual os cidadãos se reconhecem institucionalmente nas instituições enquanto determinações de sua vontade que se objetivou, ou seja, os cidadãos se reconhecem nas instituições e entre si próprios porque as reconhecem - as Instituições - como propriamente suas, resultado de sua ação mediatizada.

No processo de mediação da ação humana com vistas a realização do estatuto de cidadão na modernidade, Hegel descreve as esferas de realização da cidadania como possuindo escopos próprios, mesmo que intercambiáveis entre si, do seguinte modo:

(i) A família enquanto primeira raiz ética do Estado e primeira esfera da aquisição de direitos e primeiro círculo de efetivação e bloqueio destes mesmos direitos, exprime sua constituição interna como determinada por Membros [Glied], os quais se reconhecem e se avaliam pelo sentimento do amor, pela existência da propriedade coletivizada, pela centralidade do papel formativo da escola e pelas relações assimétricas de gênero. A cidadania exercita-se de modo imediato pela noção de pertencimento oriunda dos vínculos de parentesco. Aqui ocorre a estruturação do Eu a partir do nós.

(ii) A sociedade civil e sua função de segunda raiz ética evidencia-se no processo de proporcionar à ideia de liberdade, enquanto bem vivente, e seu ideal regulativo, a cidadania, a experiência da perda de sua unidade pela vivência do relativo e da cisão interna.

É a sociedade civil a radicalização do negativo e de sua potência inexorável, inerente a todo o vivo, ao afirmar paradoxalmente que todos os homens são iguais, são todos constituintes da sociedade civil, indivíduos. ${ }^{9}$ Todavia, a sociedade civil ainda subsume os processos de sociabilização e os de realização/efetivação de direitos à dinâmica do mercado e seus processos dilacerantes.

$\mathrm{Na}$ sociedade civil a realização do indivíduo como cidadão privado efetiva-se pela capacidade de produzir e adquirir propriedade, pelo desempenho de um trabalho, pela capacidade em fazer a riqueza circular. Os vínculos sociais são frágeis, o indivíduo é fim em si mesmo. A esta esfera, a cidadania vive o colapso de sua fissura pelo mercado e a subsunção das relações sociais à padrões mercantis. Aqui ocorre a submissão do nós ao Eu.

\footnotetext{
${ }^{9}$ Hegel, Filosofia do Direito, $\S 187,193$ entre outros.
} 
A sociedade civil realiza em toda a sua inteireza os fundamentos da modernidade, quais sejam: subjetividade atomizada, instrumentalização das relações humanas, subsunção da dimensão do político ao mercado, competição, auto-estima como sucesso pessoal etc, porém o princípio basilar sob o qual se sustenta a sociedade civil é o reconhecimento do princípio da igualdade.

Na sociedade civil burguesa se realizam, mas não se efetivam os princípios da igualdade jurídica - todos são iguais perante a ordem normativa - da igualdade social todos são por nascimento iguais em condições de participação social - da igualdade política - todos são politicamente ativos sem distinção por critérios não racionais, e se reconhece a necessidade da livre circulação da riqueza, enquanto fundamento de uma possível igualdade econômica.

Mas, porque então a cidadania não se efetiva na sociedade civil burguesa? Hegel conclui que a sociedade civil, enquanto momento da eticidade que busca efetivar um ideal de cidadania é incapaz de realizá-lo porque apenas produz

[...] uma ligação dos membros enquanto singulares autônomos, com isso, numa universalidade formal, por seus carecimentos e pela constituição jurídica, enquanto meio da segurança das pessoas e da propriedade, e por uma ordem exterior para seus interesses particulares e comuns $[\ldots]^{10}$

Tal ênfase no caráter conflitivo da sociedade civil deve-se em grande parte a sua função mediadora, de meio, entre a família e o Estado, do processo de efetivação da ideia de liberdade.

A sociedade civil põe à prova a ideia de liberdade e igualdade oriundas do princípio da subjetividade, por fazer intervir a negatividade do processo de desenvolvimento da liberdade e do laço social constituinte das sociedades complexas, produzindo um novo tipo de desigualdade e ambivalência, desconhecidas até aquele momento histórico. Daí Hegel denominá-la de a “[...] eticidade perdida em seus extremos [Extreme verlorenen Sittlichkeit $] " 11$.

O Estado na perspectiva desenvolvida na Filosofia do Direito carrega em seu conceito e em sua constituição as funções para ser não apenas uma instância de mediação dos interesses coletivos da família e privados da sociedade civil-burguesa, ocupando-se em proporcionar, oportunizar, promover e,quiçá, possivelmente efetivar o

\footnotetext{
${ }^{10}$ Hegel, Filosofia do Direito, $\$ 157$, b.

${ }^{11}$ Hegel, Filosofia do Direito, $\S 184$.
} 
interesse geral, o bem-público enquanto consciência e disposição cidadã, somente como resultado daquele processo de mediação e no seio mesmo da autodiferenciação própria dos processos de mediação.

É nesse sentido que Hegel dirá ser o estado uma faculdade e/ou poder acima das esferas privadas de efetivação da cidadania presentes na família e na sociedade civil, e ao mesmo tempo condições imanentes da garantia de efetivação da cidadania ao nível do Estado, enquanto seu fim imanente (FD, § 261). Aqui ocorre o reconhecimento do Nós no eu e do Eu no nós .

\section{À guisa de conclusão}

O movimento de explicitação da lógica imanente à Filosofia do Direito no tocante à cidadania se realiza mediante a constituição de diversas esferas de efetivação das pautas cidadãs desde a Família à Sociedade civil, consumando-se no Estado enquanto esfera que sem solução de continuação, nem solução de determinações intrínsecas a cada esfera, oportuniza as condições de efetivação da cidadania- mas não as realiza a priori - enquanto uma disposição espiritual e não como um mero atributo jurídico-procedimental, mas desde uma perspectiva substancial.

O tortuoso caminho indicado por Hegel para a realização e efetivação da cidadania à sua época é já um indício das dificuldades que tal conceito, direito ou mesmo pretensão humana enfrentou e enfrenta à sua efetiva realização, quiçá possamos compreender o diagnóstico hegeliano para, assim, melhor podermos elaborarmos o nosso.

\section{Bibliografia}

BEISER, Frederick. Hegel. Nova Iorque: Routledge, 2005.

FINK-EITEL, Henrich. Dialektik und Sozialethik - Kommentierende Untersuchugen zu Hegels „Logik”. Meisenheim am Glan: Verlag Anton Hain, 1978.

HEGEL, G.W.F. Grundlinien der Philosophie des Rechts oder Naturrecht und Staatswissenschaft im Grundrisse. Frankfurt am Main: Suhrkamp Verlag, 1970, Band. 7. Filosofia do Direito. Trad. Paulo Meneses, Agemir Bavaresco, Danilo Vaz-Curado e outros. São Paulo: Loyola/UNICAP/UNISINOS, 2010.

HÖSLE, Vittorio. Anspurch und Leistung von Rechtsphilosophie. Stuttgart-Bad Cannstatt: Frommann-holzboog, 1987. 
ILTING, Karl-Heinz. The structure of Hegel's Philosophy of Right, in Hegel's Political Philosophy. Problems and Perspectives, London:1971, p. 90-110.

INWOOD, Michael. Dicionário Hegel. São Paulo: Ed. J. Zahar, 1995.

KERVÉGAN, Jean-François. L'effectif et le rationnel - Hegel et l'esprit objectif. Paris: Vrin, 2007.

KIM, Joonsoo. Der Begriff der Freiheit bei Hegel. Frankfurt am Main/Bern/Berlin: Peter Lang, 1996.

LAKEBRINK, Bernhard. Die europäische Idee der Freiheit - Hegels Logik ud die Tradition der Selbstbestimmung. Leiden: E. J Brill, 1968.

MARMASSE, Gilles. Force et fragilité des normes - Principes de la philosophie du droit de Hegel. Paris ; PUF/CNED, 2011.

ROSENFIELD, Denis. Politique et liberté. Une étude sur la structure logique de la "Philosophie du droit" de Hegel. Paris: Aubier Montaigne, 1984.

RITTER, Joachim. Metaphysik und Politik. Studien zu Aristoteles und Hegel. Frankfurt am Main: Suhrkamp, 1969.

SIEP, L. Die Aktualität der praktischen Philosophie Hegels. In: WELSCH, W.;VIEWEG, K. (Hrsg.). Das Interesse des Denkens. Hegel aus heutiger Sicht. München:cFink, 2003, S. 191204. 